\title{
Article
}

\section{How Relative Age Effects Associate with Football Players' Market Values: Indicators of Losing Talent and Wasting Money}

\author{
Michael Romann ${ }^{1, *(\mathbb{D}, \text { Marie Javet }}{ }^{1}$, Stephen Cobley ${ }^{2}$ (D) and Dennis-Peter Born ${ }^{1,3}$ (D) \\ 1 Department for Elite Sport, Swiss Federal Institute of Sport Magglingen, 2532 Magglingen, Switzerland; \\ Marie.Javet@baspo.admin.ch (M.J.); dennis.born@swiss-aquatics.ch (D.-P.B.) \\ 2 Faculty of Health Science, University of Sydney, Lidcombe, NSW 2141, Australia; \\ stephen.cobley@sydney.edu.au \\ 3 Swiss Swimming Federation, 3063 Berne, Switzerland \\ * Correspondence: michael.romann@baspo.admin.ch
}

check for updates

Citation: Romann, M.; Javet, M.; Cobley, S.; Born, D.-P. How Relative Age Effects Associate with Football Players' Market Values: Indicators of Losing Talent and Wasting Money. Sports 2021, 9, 99. https://doi.org/ $10.3390 /$ sports 9070099

Academic Editors: Adam Leigh Kelly, Sergio L. Jiménez Sáiz, Sara Diana Leal dos Santos and Alberto Lorenzo Calvo

Received: 28 May 2021

Accepted: 7 July 2021

Published: 9 July 2021

Publisher's Note: MDPI stays neutral with regard to jurisdictional claims in published maps and institutional affiliations.

Copyright: (c) 2021 by the authors. Licensee MDPI, Basel, Switzerland. This article is an open access article distributed under the terms and conditions of the Creative Commons Attribution (CC BY) license (https:/ / creativecommons.org/licenses/by/ $4.0 /)$.
Abstract: Background: In football, annual age-group categorization leads to relative age effects (RAEs) in talent development. Given such trends, relative age may also associate with market values. This study analyzed the relationship between RAEs and market values of youth players. Methods: Age category, birthdate, and market values of 11,738 youth male football players were obtained from the "transfermarkt.de" database, which delivers a good proxy for real market values. RAEs were calculated using odds ratios (OR) with 95\% confidence intervals (95\%CI). Results: Significant RAEs were found across all age-groups $(p<0.05)$. The largest RAEs occurred in U18 players (Q1 [relatively older] v Q4 [relatively younger] OR =3.1) ORs decreased with age category, i.e., U19 (2.7), U20 (2.6), U21 (2.4), U22 (2.2), and U23 (1.8). At U19s, Q1 players were associated with significantly higher market values than Q4 players. However, by U21, U22, and U23 RAEs were inversed, with correspondingly higher market values for Q4 players apparent. While large typical RAEs for all playing positions was observed in younger age categories (U18-U20), inversed RAEs were only evident for defenders (small-medium) and for strikers (medium-large) in U21-U23 (not goalkeepers and midfielders). Conclusions: Assuming an equal distribution of football talent exists across annual cohorts, results indicate the selection and market value of young professional players is dynamic. Findings suggest a potential biased selection, and undervaluing of Q4 players in younger age groups, as their representation and market value increased over time. By contrast, the changing representations and market values of Q1 players suggest initial overvaluing in performance and monetary terms. Therefore, this inefficient talent selection and the accompanying waste of money should be improved.

Keywords: talent selection; talent development; return of investment; market value; drafts

\section{Introduction}

During childhood and adolescence, young football players are categorized by annual age groups. However, the chronological age gap of up to 12 months between players born in early (January) and late (December) in the year leads to substantial differences in performance and biased talent selection decisions [1,2]. The result of participation or selection bias, specifically the overrepresentation of chronologically older soccer players within one age category, is called relative age effects (RAEs). RAEs have been shown to affect talent development systems in a wide range of team and individual sports, e.g., ice hockey, football, swimming, tennis, in both females and males from 4 years of age to adulthood [2,3]. Relatively older children within annual cohorts are more likely to be selected in talent development teams, with selection commensurate with additional training, and access to higher quality coaching likely leading to accumulated performance advantages [4,5]. By contrast, the relatively younger children are underrepresented, are less likely to be selected to talent development systems, and are more likely to withdraw from 
the sport [6-8]. Interestingly, research has subsequently shown how relatively younger players, who are selected for a talent development system, actually have a greater chance of becoming a professional player than their relatively older counterparts [9]. Such observations have become synonymous with the proposition of a "underdog hypothesis" [10]. In talent development contexts, late-born players have been shown to be more likely to achieve senior professional status, as they may benefit more from competitive play with their older counterparts [10-12]; that said multiple factors and processes may contribute to the outcome. Furthermore, a study of German professional soccer players has shown that players born late $(\mathrm{Q} 4)$ had systematically higher wages than their fellow $\mathrm{Q} 1$ players [13].

For football clubs, the capability to accurately identify athletic potential, and recruit potential, in the early stages of development has several organisational benefits [14]. Given how athletic talent can influence team achievements, being able to secure athletic potential can have performance benefit [15]. That said, research which examines the hiring decisions in professional sports, recognized the difficulty of being able to accurately identify youthful talent, which may lead to future performance productivity [16].

In addition to the traditional assessment methods of talent scouts, fans and football experts have established a large online community called "transfermarkt.de". Transfermarkt.de assesses the market value of professional footballer players at an age range from U15 to retirement. The community has become the main source for reporting on market values $[17,18]$. From an economic perspective, the aim of many professional football clubs is to buy undervalued players to achieve both higher performance and higher returns on investment [18]. Moreover, a rapidly growing body of literature emphasizes the importance of collective judgements for assessing actual and future values $[17,19]$. Recent studies showed that the variance of actual transfer fees paid (for players) in the German Bundesliga can almost entirely be explained $\left(R^{2}=0.90\right)$ by the market values reported on transfermarkt.de [17]. Current literature suggests that player market values on transfermarkt.de are good proxy estimate indicators of current as well as future players' real market values and will, therefore, play an increasing role in talent recruitment, sports economics and talent development $[17,19]$.

Given the relevance of RAEs and market values for professional soccer clubs this study had two objectives. The first objective was to identify the presence of (changing) RAEs in professionally contracted players across the developmental to professional years (e.g., 18-23 years of age). The second objective was to assess the relationship between RAEs and player market values (as indicated on Transfermarkt) and whether age-group and playing position moderated the relationship.

\section{Materials and Methods}

\subsection{Participants}

Participants were $n=11,738$ players included in this study. Inclusion criteria were 2000 players with the highest market valuein every age categories from U18 to U23. In the U18 category all 1738 listed players were analysed (Table 1).

Table 1. Subject characteristics per age category.

\begin{tabular}{|c|c|c|c|c|c|c|}
\hline $\begin{array}{l}\text { under } \\
\text { (U) }\end{array}$ & $\mathbf{n}$ & $\begin{array}{c}\text { Age } \\
\text { (Years) }\end{array}$ & $\begin{array}{l}\text { Height } \\
\text { (cm) }\end{array}$ & Market Value (€) & $\begin{array}{c}\mathbf{n} \\
\text { (Clubs) }\end{array}$ & $\stackrel{n}{\text { (Countries) }}$ \\
\hline 18 & 1738 & $17.4 \pm 0.5$ & $180.0 \pm 7.0$ & $326,252 \pm 1,878,569$ & 941 & 98 \\
\hline 19 & 2000 & $18.6 \pm 0.3$ & $180.6 \pm 6.8$ & $399,588 \pm 1,957,796$ & 1149 & 105 \\
\hline 20 & 2000 & $19.6 \pm 0.3$ & $180.5 \pm 7.0$ & $853,200 \pm 4,360,673$ & 1140 & 110 \\
\hline 21 & 2000 & $20.6 \pm 0.3$ & $180.6 \pm 6.9$ & $1,255,337 \pm 4,761,941$ & 1118 & 118 \\
\hline 22 & 2000 & $21.6 \pm 0.3$ & $180.6 \pm 6.8$ & $1,367,525 \pm 6,070,609$ & 1119 & 119 \\
\hline 23 & 2000 & $22.6 \pm 0.3$ & $180.8 \pm 6.9$ & $1,968,675 \pm 5,863,952$ & 1077 & 117 \\
\hline Total & 11,738 & $20.1 \pm 1.7$ & $180.6 \pm 6.9$ & $1,043,561 \pm 4,552,652$ & 2861 & 153 \\
\hline
\end{tabular}

Note: Data presented as mean \pm the standard deviation or frequency (n). 
Data were provided by the owner of the open-source football database transfermarkt.de, with permission to anonymously analyse and publish the results. All data were extracted on 17 July 2020 and included current data of players age, height, market value, club and nationality. The website provides independent estimates of players' market value and is regularly updated (last update in March 2020) by more than 190,000 professional and non-professional individuals with the approval of Transfermarkt.de experts [17,20]. Transfermarkt.de has been used in several previous studies [20-23], and has been shown to be a valid and useful database for game performance indicators and market values [17]. Data exported for this study included birthdate, market value, nationality, club and playing position. The study was pre-approved by the institutional review board of the Swiss Federal Institute of Sport Magglingen (Reg.-Nr. HLP-2021-131) and is in accordance with the Declaration of Helsinki.

\subsection{Procedures and Data Analysis}

The cut-off date for age group selections in international football in all countries and according to FIFA rules is 1 January. Players were categorized into four relative age quarters (Q) and two relative age semesters (S) according to their birth month, independently of birth year (i.e., S1 = January to June; S2 = July to December and Q1 = January to March; Q2 = April to June; Q3 = July to September; and Q4 = October to December). Due to the multi-nation sample $(n=152)$ within the current investigation, potential national differences in birth rates per month could not be taken into consideration which has to be considered as a limitation. Therefore, equal distribution of births across all months and years was assumed for the expected birth distribution of the general population [1,5]. The following age categories were analysed for their relative age distributions: U18 to U23. RAEs were calculated using odds ratios (OR; Q1 vs. Q4) with 95\% confidence intervals (95\%CI). The OR was interpreted as an effect size as follows: we assumed a significant RAE if the CI did not include 1 and interpreted $1.00 \leq \mathrm{OR}<1.22,1.22 \leq \mathrm{OR}<1.86,1.86 \leq \mathrm{OR}<3.00$, and $\mathrm{OR} \geq 3.00$, as negligible, small, medium and large, respectively [24]. If the OR was $<1$ and the CI did not include 1 , this finding was interpreted as a significant inverse RAE. Inverse ORs $<0.33(1 / 3), 0.33 \leq$ OR $<0.53(1 / 1.86), 0.53 \leq$ OR $<0.81,0.81 \leq$ OR $<1.0$ were, respectively, interpreted as large, medium, small, and negligible. Market values were extracted in $€$, playing positions were categorized as goalkeepers, defenders (central and outside), midfielders (central and outside) and strikers. Using these data mean market values per age category and $Q$ were calculated using crosstabulations. In a second step the difference of observed and expected market values $(\Delta)$ were calculated. Observed market values were the sum of the market values of all players per age category and per Q. Estimated market values were calculated in the same way, but with the assumption of an equal distribution of players per Q. For instance, if the expected number of players in each $Q$ is 500 , the observed number in Q4 is 400 and the mean market value of the Q4players of the age category is $1,000,000 €$, the calculated $\Delta$ is $400-500=-100 \times 1,000,000 €=-100,000,000 €$.

\section{Results}

Distribution of players per Q with 95\% CI are illustrated in Table 2. There were medium RAEs in the U18 to U22 and small RAEs in the U23. With a large OR of 3.1, RAEs were highest in the youngest age category (U18) and consistently/continuously decreases to small RAEs demonstrated by an OR of 1.8 in the U23 (Table 2).

Table 3 shows market values across each age group and all playing positions separated by birth quartile. In the U19 a small effect with an OR of 1.2 was found. The RAEs in the U18, U20, and U21 were negligible. A medium inverse effect (OR 0.5 [95\%CI 0.4, 0.5]), where Q4 players had a higher market value, were found in the U22 and a small effect in the U23 (OR 0.7 [95\%CI 0.6, 0.8]).

Table 4 shows the difference of observed and expected market values across each age group and Q. In Q1 and Q2 observed values were constantly higher than expected values. In contrast, in Q3 and Q4 observed values were constantly lower than expected. 
Within the age categories, there was a constant decrease in values from Q1 to Q4. In the overall group, this leads to a deviation/overestimation of $€ 1.2$ billion in $\mathrm{Q} 1$ and a deviation/underestimation of $€ 1.4$ billion in Q4.

Table 2. Distribution of players per age category and quarter (Q).

\begin{tabular}{ccccccccc}
\hline under (U) & $\mathbf{n}$ & $\mathbf{Q 1}$ & $\mathbf{Q} 2$ & $\mathbf{Q 3}$ & $\mathbf{Q 4}$ & OR Q1/Q4 & 95\% CI & Effect Size \\
\hline 18 & 1738 & $705(40.6 \%)$ & $462(26.6 \%)$ & $340(19.6 \%)$ & $231(13.3 \%)$ & $3.1^{*}$ & $(2.6,3.6)$ & large \\
19 & 2000 & $746(37.3 \%)$ & $574(28.7 \%)$ & $402(20.1 \%)$ & $278(13.9 \%)$ & $2.7^{*}$ & $(2.3,3.1)$ & medium \\
20 & 2000 & $783(39.2 \%)$ & $509(25.5 \%)$ & $410(20.5 \%)$ & $298(14.9 \%)$ & $2.6^{*}$ & $(2.3,3.0)$ & medium \\
21 & 2000 & $722(36.1 \%)$ & $537(26.9 \%)$ & $439(22 \%)$ & $302(15.1 \%)$ & $2.4 *$ & $(2.1,2.8)$ & medium \\
22 & 2000 & $700(35 \%)$ & $560(28 \%)$ & $417(20.9 \%)$ & $323(16.2 \%)$ & $2.2 *$ & $(1.9,2.5)$ & medium \\
23 & 2000 & $659(33 \%)$ & $531(26.6 \%)$ & $452(22.6 \%)$ & $358(17.9 \%)$ & $1.8 *$ & $(1.6,2.1)$ & small \\
\hline \multirow{2}{*}{ Total } & 11,738 & 4315 & $3173(27 \%)$ & $2460(21 \%)$ & 1790 & \multirow{2}{*}{$2.4 *$} & $(2.2,2.6)$ & medium \\
\hline
\end{tabular}

Note: RAEs of players listed in Tranfermarkt.de. Q1 to Q4 = Quartile 1 to $4 ; \mathrm{OR}=$ Odds ratio; $\mathrm{CI}=$ Confidence Interval; ${ }^{*} p<0.05 ; \mathrm{OR}<1.22$, $1.22 \leq \mathrm{OR}<1.86,1.86 \leq \mathrm{OR}<3.00$, and $\mathrm{OR} \geq 3.00$, was interpreted as negligible, small, medium and large.

Table 3. Mean market values per age category and relative age quartile (Q).

\begin{tabular}{ccccccccc}
\hline $\begin{array}{c}\text { under } \\
(\mathbf{U})\end{array}$ & $\mathbf{n}$ & $\mathbf{Q 1}(\boldsymbol{\xi})$ & $\mathbf{Q 2}(\boldsymbol{(})$ & $\mathbf{Q 3}(\boldsymbol{\xi})$ & $\mathbf{Q 4}(\boldsymbol{(})$ & $\begin{array}{c}\text { OR } \\
\mathbf{Q 1 / Q 4}\end{array}$ & $\mathbf{9 5 \%} \mathbf{C I}$ & $\begin{array}{c}\text { Effect } \\
\text { Size }\end{array}$ \\
\hline 18 & 1738 & 318,950 & 320,963 & 328,971 & 327,597 & 1.0 & $(0.9,1.0)$ & no \\
19 & 2000 & 469,437 & 373,563 & 317,910 & 383,993 & $1.2^{*}$ & $(1.1,1.3)$ & small \\
20 & 2000 & 942,593 & 711,690 & 809,939 & 919,547 & 1.0 & $(1.0,1.0)$ & non \\
21 & 2000 & $1,183,587$ & $1,311,778$ & $1,252,790$ & $1,330,215$ & $0.9 *$ & $(0.9,0.9)$ & non \\
22 & 2000 & $1,136,464$ & $1,285,982$ & $1,052,338$ & $2,416,563$ & $0.5^{*}$ & $(0.5,0.5)$ & medium \\
23 & 2000 & $1,789,416$ & $2,112,712$ & $1,519,967$ & $2,651,536$ & $0.7^{*}$ & $(0.7,0.7)$ & small \\
\hline Total & 11,738 & 960,002 & $1,031,007$ & 913,638 & $1,445,796$ & $0.7^{*}$ & $(0.6,0.7)$ & small \\
\hline
\end{tabular}

Note: Q1 to Q4 = Quartile 1 to 4 ; OR = Odds Ratio; CI = Confidence Interval; * $p<0.05 ; 1.00 \leq \mathrm{OR}<1.22$, $1.22 \leq \mathrm{OR}<1.86,1.86 \leq \mathrm{OR}<3.00$, and $\mathrm{OR} \geq 3.00$, was interpreted as negligible, small, medium and large Inverse ORs $<0.33(1 / 3), 0.33 \leq \mathrm{OR}<0.53(1 / 1.86), 0.53 \leq \mathrm{OR}<0.81,0.81 \leq \mathrm{OR}<1.0$ were interpreted as large, medium, small and negligible.

Table 4. $\Delta$ of total market values per age category and relative age quartile (Q).

\begin{tabular}{cccccc}
\hline under $(\mathbf{U})$ & $\mathbf{n}$ & $\boldsymbol{\Delta} \mathbf{Q 1}(\boldsymbol{\epsilon})$ & $\boldsymbol{\Delta} \mathbf{Q} 2(\boldsymbol{\epsilon})$ & $\boldsymbol{\Delta} \mathbf{Q 3}(\boldsymbol{\epsilon})$ & $\boldsymbol{\Delta} \mathbf{Q 4}(\boldsymbol{\epsilon})$ \\
\hline 18 & 1738 & $86,276,071$ & $8,826,488$ & $-31,087,721$ & $-66,666,071$ \\
19 & 2000 & $115,481,501$ & $27,643,641$ & $-31,155,224$ & $-85,246,403$ \\
20 & 2000 & $266,753,704$ & $6,405,206$ & $-72,894,512$ & $-185,748,490$ \\
21 & 2000 & $262,756,371$ & $48,535,801$ & $-76,420,216$ & $-263,382,616$ \\
22 & 2000 & $227,292,857$ & $77,158,929$ & $-87,344,065$ & $-427,731,734$ \\
23 & 2000 & $284,517,109$ & $65,494,068$ & $-72,958,407$ & $-376,518,156$ \\
\hline Total & 11,738 & $1,243,077,614$ & $234,064,133$ & $-371,860,145$ & $-1,405,293,470$ \\
\hline
\end{tabular}

Note: Difference of observed and expected market values $(\Delta)$. Q1 to Q4 = Quartile 1 to 4 .

Distribution of player positions per Q with $95 \%$ CI are illustrated in Table 5. There were medium to large RAEs in all positions from U18 to U22. The highest ORs were found in the U18 age category, except for goalkeepers. There were no significant differences between the different playing positions. 
Table 5. Distribution of player positions per age category and quarter (Q).

\begin{tabular}{|c|c|c|c|c|c|c|c|c|c|}
\hline Position & under (U) & $\mathbf{n}$ & Q1 (\%) & Q2 (\%) & Q3 (\%) & Q4 (\%) & OR Q1/Q4 & $95 \%$ CI & Effect Size \\
\hline \multirow{6}{*}{ Goalkeeper } & 18 & 240 & 89 (37.1) & 65 (27.1) & $49(20.4)$ & 37 (15.4) & $2.4 *$ & $(2.3,2.5)$ & medium \\
\hline & 19 & 191 & $67(35.1)$ & $52(27.2)$ & $44(23.0)$ & $28(14.7)$ & $2.4 *$ & $(2.3,2.5)$ & medium \\
\hline & 20 & 149 & 62 (41.6) & $38(25.5)$ & $30(20.1)$ & 19 (12.8) & $3.3 *$ & $(3.1,3.4)$ & large \\
\hline & 21 & 144 & $55(38.2)$ & $34(23.6)$ & $27(18.8)$ & $28(19.4)$ & $2.0 *$ & $(1.9,2.1)$ & medium \\
\hline & 22 & 109 & $43(39.4)$ & $31(28.4)$ & $23(21.1)$ & $12(11.0)$ & 3.6 * & $(3.4,3.7)$ & large \\
\hline & 23 & 114 & 39 (34.2) & 35 (30.7) & $21(18.4)$ & $19(16.7)$ & $2.1 *$ & $(2.0,2.1)$ & medium \\
\hline \multirow{6}{*}{ Defender } & 18 & 431 & 212 (49.2) & $114(26.5)$ & $89(20.6)$ & $50(11.6)$ & $4.2 *$ & $(4.0,4.4)$ & large \\
\hline & 19 & 558 & $226(40.5)$ & 161 (28.9) & $101(18.1)$ & $70(12.5)$ & $3.2 *$ & $(3.1,3.4)$ & large \\
\hline & 20 & 560 & 219 (39.1) & $143(25.5)$ & $116(20.7)$ & 82 (14.6) & $2.7 *$ & $(2.6,2.8)$ & medium \\
\hline & 21 & 609 & $230(37.8)$ & 165 (27.1) & $120(19.7)$ & $94(15.4)$ & 2.4 * & $(2.4,2.6)$ & medium \\
\hline & 22 & 639 & 224 (35.1) & $169(26.4)$ & $136(21.3)$ & 110 (17.2) & $2.0 *$ & $(2.0,2.1)$ & medium \\
\hline & 23 & 676 & $238(35.2)$ & $172(25.4)$ & $144(21.3)$ & $122(18)$ & $2.0 *$ & $(1.9,2.0)$ & medium \\
\hline \multirow{6}{*}{ Midfielder } & 18 & 606 & $236(38.9)$ & $164(27.1)$ & $119(19.6)$ & 87 (14.4) & $2.7 *$ & $(2.6,2.8)$ & medium \\
\hline & 19 & 711 & 255 (35.9) & $218(30.7)$ & 141 (19.8) & 97 (13.6) & $2.6 *$ & $(2.5,2.7)$ & medium \\
\hline & 20 & 713 & $272(38.1)$ & $183(25.7)$ & $144(20.2)$ & $114(16.0)$ & 2.4 * & $(2.3,2.5)$ & medium \\
\hline & 21 & 681 & $243(35.7)$ & $173(25.4)$ & $171(25.1)$ & $94(13.8)$ & $2.6^{*}$ & $(2.5,2.7)$ & medium \\
\hline & 22 & 669 & $250(37.4)$ & $204(30.5)$ & 120 (17.9) & 95 (14.2) & 2.6 * & $(2.5,2.7)$ & medium \\
\hline & 23 & 627 & 179 (28.5) & 179 (28.5) & 155 (24.7) & $114(18.2)$ & $1.6^{*}$ & $(1.5,1.6)$ & small \\
\hline \multirow{6}{*}{ Striker } & 18 & 461 & $202(43.8)$ & 119 (25.8) & 83 (18) & 57 (12.4) & $3.5 *$ & $(3.4,3.7)$ & large \\
\hline & 19 & 540 & $198(36.7)$ & $143(26.5)$ & $116(21.5)$ & 83 (15.4) & $2.4 *$ & $(2.3,2.5)$ & medium \\
\hline & 20 & 578 & 230 (39.8) & 145 (25.1) & 120 (20.8) & $83(14.4)$ & $2.8 *$ & $(2.7,2.9)$ & medium \\
\hline & 21 & 566 & 194 (34.3) & $165(29.2)$ & $121(21.4)$ & 86 (15.2) & $2.3 *$ & $(2.2,2.4)$ & medium \\
\hline & 22 & 583 & $183(31.4)$ & $156(26.8)$ & $138(23.7)$ & $106(18.2)$ & $1.7 *$ & $(1.6,1.8)$ & small \\
\hline & 23 & 583 & $203(34.8)$ & 145 (24.9) & 132 (22.6) & 103 (17.7) & $2.0 *$ & $(1.9,2.1)$ & medium \\
\hline
\end{tabular}

Note: Q1 to Q4 = Quartile 1 to $4 ; \mathrm{OR}=$ Odds Ratio; $\mathrm{CI}=$ Confidence Interval; ${ }^{*} p<0.05 ; 1.00 \leq \mathrm{OR}<1.22,1.22 \leq \mathrm{OR}<1.86,1.86 \leq \mathrm{OR}<3.00$, and $\mathrm{OR} \geq 3.00$, was interpreted as negligible, small, medium and large.

Table 6 displays position specific RAEs between Q1 and Q4 players for each age group based on market values. Market value was greater for relatively older goalkeepers (Q)1 compared to Q4, with a small to large effect depending on age group. The market values of defenders, midfielders and strikers were significantly higher for Q4 compared to Q1 players in the U21, U22 and U23 with small to large effects. Over- and undervaluing due to RAEs were highest for strikers, followed by defenders, midfielders, and goalkeepers.

Table 6. Market values per playing position, age category and relative age quartile (Q).

\begin{tabular}{|c|c|c|c|c|c|c|c|c|c|}
\hline Position & under (U) & $\mathbf{n}$ & Q1 (€) & Q2 (€) & Q3 (€) & Q4 (€) & OR Q1/Q4 & $95 \%$ CI & Effect Size \\
\hline \multirow{6}{*}{ Goalkeeper } & 18 & 240 & 159,238 & 140,860 & 33,724 & 24,024 & $6.6^{*}$ & $(6.4,6.9)$ & large \\
\hline & 19 & 191 & 107,090 & 90,385 & 101,705 & 83,929 & $1.3^{*}$ & $(1.2,1.3)$ & small \\
\hline & 20 & 149 & 318,548 & 265,789 & 251,667 & 236,842 & $1.3^{*}$ & $(1.3,1.4)$ & small \\
\hline & 21 & 144 & $1,750,909$ & 217,647 & 432,407 & 413,393 & $4.2 *$ & $(4.0,4.4)$ & large \\
\hline & 22 & 109 & 786,628 & $1,112,903$ & 370,652 & 581,250 & $1.4^{*}$ & $(1.3,1.4)$ & small \\
\hline & 23 & 114 & $2,008,333$ & $1,289,286$ & $1,257,143$ & 707,895 & $2.8^{*}$ & $(2.7,3.0)$ & medium \\
\hline \multirow{6}{*}{ Defender } & 18 & 431 & 192,191 & 265,570 & 114,326 & 74,500 & $2.6^{*}$ & $(2.5,2.7)$ & medium \\
\hline & 19 & 558 & 473,341 & 385,093 & 135,891 & 261,786 & $1.8^{*}$ & $(1.7,1.9)$ & medium \\
\hline & 20 & 560 & 689,954 & 455,944 & 560,129 & $1,484,146$ & 0.5 * & $(0.5,0.5)$ & medium \\
\hline & 21 & 609 & $1,016,739$ & $1,233,636$ & $1,392,292$ & $1,347,340$ & $0.8^{*}$ & $(0.7,0.8)$ & small \\
\hline & 22 & 639 & $1,221,205$ & 999,260 & 767,463 & $2,872,045$ & $0.4^{*}$ & $(0.4,0.4)$ & medium \\
\hline & 23 & 676 & $1,457,248$ & $1,458,285$ & $1,083,854$ & $2,216,189$ & 0.7 * & $(0.6,0.7)$ & small \\
\hline \multirow{6}{*}{ Midfielder } & 18 & 606 & 501,907 & 334,146 & 271,639 & 245,690 & $2.0 *$ & $(2.0,2.1)$ & medium \\
\hline & 19 & 711 & 288,431 & 329,128 & 324,823 & 177,835 & $1.6^{*}$ & $(1.6,1.7)$ & small \\
\hline & 20 & 713 & 694,210 & 877,869 & 479,688 & 664,035 & 1.0 * & $(1,0,1.1)$ & non \\
\hline & 21 & 681 & $1,331,173$ & $1,533,671$ & $1,350,585$ & 615,160 & 2.2 * & $(2.08,2.3)$ & medium \\
\hline & 22 & 669 & $1,311,600$ & $1,616,299$ & $1,373,958$ & $1,462,895$ & $0.9^{*}$ & $(0.9,0.9)$ & non \\
\hline & 23 & 627 & $2,199,581$ & $2,425,279$ & $1,407,903$ & $2,472,368$ & 0.9 * & $(0.9,0.9)$ & non \\
\hline \multirow{6}{*}{ Striker } & 18 & 461 & 318,688 & 492,731 & 808,735 & 863,158 & $0.4^{*}$ & $(0.4,0.4)$ & medium \\
\hline & 19 & 540 & 820,707 & 531,294 & 550,000 & 829,217 & 1.0 & $(1.0,1.0)$ & non \\
\hline & 20 & 578 & $1,645,109$ & 871,034 & $1,587,292$ & 868,976 & $1.9^{*}$ & $(1.8,2.0)$ & medium \\
\hline & 21 & 566 & $1,035,696$ & $1,382,727$ & $1,159,298$ & $2,391,570$ & $0.4^{*}$ & $(0.4,0.5)$ & medium \\
\hline & 22 & 583 & 875,683 & $1,199,038$ & $1,167,029$ & $3,006,368$ & 0.3 * & $(0.3,0.3)$ & large \\
\hline & 23 & 583 & $1,775,123$ & $2,701,897$ & $2,169,129$ & $3,724,029$ & $0.5^{*}$ & $(0.5,0.5)$ & medium \\
\hline
\end{tabular}

Note: Difference of observed and expected market values $(\Delta)$. Q1 to Q4 = Quartile 1 to $4 ; \mathrm{OR}=$ Odds Ratio; $\mathrm{CI}=\mathrm{Confidence} \mathrm{Interval;}{ }^{*} p<0.05$; $1.00 \leq \mathrm{OR}<1.22,1.22 \leq \mathrm{OR}<1.86,1.86 \leq \mathrm{OR}<3.00$, and $\mathrm{OR} \geq 3.00$, was interpreted as negligible, small, medium and large. Inverse

ORs $<0.33(1 / 3), 0.33 \leq \mathrm{OR}<0.53(1 / 1.86), 0.53 \leq \mathrm{OR}<0.81,0.81 \leq \mathrm{OR}<1.0$ were interpreted as large, medium, small and negligible. 


\section{Discussion}

Results from the present study, illustrate the following main findings: (i) the analysis of relative age distribution illustrated significant overrepresentations of Q1 players in all age categories. Effect sizes diminished progressively from the U18 (large) to the U23 (small). This trend only existed when analyzing the whole sample, not when separated by playing positions. (ii) Relative age was also associated with biased market values. Initially, higher market values were apparent for Q1 players at U19. Thereafter, the effect was inversed, with Q4 players showing a significantly higher market value across U21, U22, and U23. (iii) Playing positions analysis revealed higher market values for Q4 defenders, midfielders, and strikers at U23, compared to Q1. By contrast, relatively older goalkeepers (Q1) had a higher market value than $\mathrm{Q} 4$ goalkeepers in all age categories.

Present findings align with previous studies, where RAEs biases were evident in the sample [2]. Biased selection during youth talent development programs may reduce a relatively younger athlete's chances of succeeding later in their career. The relatively younger are disadvantaged by lower selection quotas, which in turn may lead to less competition experience, lower motivation, as well as a lower opportunities of accessing high-quality training [2]. However, particular RAE studies identify inverse RAEs in talent development programs post-puberty $[9,12]$, suggesting delayed benefits if the relatively young can remain within the sporting development system. For instance, Deaner (2013) showed how compared to those born in Q1, Q3 and Q4 players were twice as likely to reach professional career benchmarks. Similarly, Fumarco (2017) identified how Q4 players scored more often, and receive higher salaries, than Q1 players. When considered alongside present findings, the underdog effect is supported, reflected by the increased likelihood of being drafted, career length, performance productivity, and now market value at the professional level [25].

The phenomenon that Q4 athletes are over-represented among those who successfully transition from youth systems to senior professional status has been called the 'underdog hypothesis'. Being younger essentially facilitates long-term development by necessitating them to overcome the relative age disadvantage, through being challenged by their older and more advanced peers [10-12]. A previous study by Doyle and Bottomley (28), who analyzed the market values of the top 1000 players on transfermarkt.de in the season of 2013-2014, noted that relatively older players had greater opportunities due to assessment selection bias, but were valued equally to players born later in the year. Although the current study confirms these results, the market values of players do represent the underdog effect. As such, selected Q4 players are often initially undervalued, but later are valued higher than Q1 players [9]. Additionally, a recent study of Perez-Gonzalez et al. [26] analyzed the market value of 2577 adult professional players of the biggest European football leagues. Small to medium RAEs were shown in all leagues $(p<0.05)$. However, this bias did not affect the market value of the professional elite soccer players examined. The authors concluded that identification and promotion of talent at young ages are often biased by RAEs, however once players have reached the professional stage, their market value is independent of RAEs [26]. In our study, from a return of investment point of view, market value of Q1 players increases by $560 \%$ from U18 to U23, whereas market value of Q4 players increases by $810 \%$. This phenomenon is even more pronounced when differentiated by playing position. The value of $\mathrm{Q} 4$ goalkeepers and defenders increases by approximately $3000 \%$, while the value of Q1 players "only" increases by $1260 \%$ and $760 \%$, respectively. In the U23, the highest mean values in terms of playing positions were found for defenders, midfielders and strikers born in Q4, except for goalkeepers. This leads to the assumption that the underdog effect exists as well if the sample is subdivided by playing positions. To sum up, RAEs and biased market values likely lead to inefficient selection and return of investment of football talent. To gain further insight into this issue, longitudinal studies analyzing the evolution of market values of players throughout talent development should be conducted. 
Limitations: while the present analysis was performed using a cross sectional dataset, future studies should use a longitudinal design to analyze the evolution of market values and their interrelationships with RAEs. Furthermore, as financial loss due to overand undervaluing was calculated on a theoretical estimate assuming an equal distribution of players between birth quarters, future studies which particularly focus on this aspect, should also include factors such as the evolution of market values in the long run, differences between female and male sports and the optimal talent development from a sports-scientific and economic point of view.

\section{Conclusions}

The analysis of relative age distribution illustrated significant overrepresentations of Q1 players in all age categories. This trend only existed when analyzing the whole sample, not when separated by playing positions. Relative age was also associated with biased market values. Initially, higher market values were apparent for Q1 players at U19. Thereafter, the effect was inversed, with Q4 players showing a significantly higher market value across U21, U22, and U23. Playing positions analysis revealed higher market values for Q4 defenders, midfielders, and strikers at U23, compared to Q1. By contrast, relatively older goalkeepers $(\mathrm{Q} 1)$ had a higher market value than $\mathrm{Q} 4$ goalkeepers in all age categories. Assuming an equal distribution of football talent exists across annual cohorts, findings suggest the selection and market value of young professional players is dynamic. Findings suggest a potential biased selection, and undervaluing of Q4 players in younger age groups, as their representation and market value increased over time. By contrast, the changing representations and market values of Q1 players suggest initial overvaluing in performance and monetary terms.

Author Contributions: Conceptualization, M.R., M.J., S.C., D.-P.B.; methodology, M.R., M.J., D.-P.B.; validation, M.R., M.J., S.C., D.-P.B.; formal analysis, M.R., D.-P.B.; investigation, M.R., M.J., S.C., D.-P.B.; data curation, M.R., D.-P.B.; writing—original draft preparation, M.R.; writing—review and editing, M.R., M.J., S.C., D.-P.B.; visualization, M.R., D.-P.B.; supervision, D.-P.B.; project administration, M.R. All authors have read and agreed to the published version of the manuscript.

Funding: This research received no external funding.

Institutional Review Board Statement: The study was conducted according to the guidelines of the Declaration of Helsinki and approved by the Institutional Review Board (or Ethics Committee) of the Swiss Federal Institute of Sport Magglingen (Reg.-Nr. HLP-2021-131).

Informed Consent Statement: Patient consent was waived due to the analysis of secondary data which is available on the website www.transfermarkt.de (accessed on 17 July 2020).

Data Availability Statement: All data used in this study are available on the website www.transfermarkt. de (accessed on 17 July 2020).

Acknowledgments: We want to thank www.transfermarkt.de (accessed on 17 July 2020) for providing the data.

Conflicts of Interest: The authors declare no conflict of interest.

\section{References}

1. Smith, K.L.; Weir, P.L.; Till, K.; Romann, M.; Cobley, S. Relative Age Effects across and within Female Sport Contexts: A Systematic Review and Meta-Analysis. Sports Med. 2018, 48, 1451-1478. [CrossRef] [PubMed]

2. Cobley, S.; Baker, J.; Wattie, N.; McKenna, J. Annual Age-Grouping and Athlete Development. Sports Med. 2009, 39, $235-256$. [CrossRef]

3. Romann, M.; Rössler, R.; Javet, M.; Faude, O. Relative Age Effects in Swiss Talent Development-A Nationwide Analysis of All Sports. J. Sports Sci. 2018, 36, 2025-2031. [CrossRef] [PubMed]

4. Wattie, N.; Schorer, J.; Baker, J. The Relative Age Effect in Sport: A Developmental Systems Model. Sports Med. 2015, 45, 83-94. [CrossRef] [PubMed]

5. Helsen, W.F.; Van Winckel, J.; Williams, A.M. The Relative Age Effect in Youth Soccer across Europe. J. Sports Sci. 2005, 23, 629-636. [CrossRef] [PubMed] 
6. Cobley, S.P.; Till, K. Participation Trends According to Relative Age across Youth UK Rugby League. Int. J. Sports Sci. Coach. 2017, 12, 339-343. [CrossRef]

7. Helsen, W.F.; Starkes, J.L.; Van Winckel, J. The Influence of Relative Age on Success and Dropout in Male Soccer Players. Am. J. Hum. Biol. Off. J. Hum. Biol. Assoc. 1998, 10, 791-798. [CrossRef]

8. Romann, M.; Rüeger, E.; Hintermann, M.; Kern, R.; Faude, O. Origins of Relative Age Effects in Youth Football—A Nationwide Analysis. Front. Sports Act. Living 2020, 2, 591072. [CrossRef]

9. Deaner, R.O.; Lowen, A.; Cobley, S. Born at the Wrong Time: Selection Bias in the NHL Draft. PLoS ONE 2013,8 , e57753. [CrossRef]

10. Gibbs, B.G.; Jarvis, J.A.; Dufur, M.J. The Rise of the Underdog? The Relative Age Effect Reversal among Canadian-Born NHL Hockey Players: A Reply to Nolan and Howell. Int. Rev. Sociol. Sport 2012, 47, 644-649. [CrossRef]

11. Kelly, A.L.; Wilson, M.R.; Gough, L.A.; Knapman, H.; Morgan, P.; Cole, M.; Jackson, D.T.; Williams, C.A. A Longitudinal Investigation into the Relative Age Effect in an English Professional Football Club: Exploring the 'Underdog Hypothesis'. Sci. Med. Footb. 2020, 4, 111-118. [CrossRef]

12. Fumarco, L.; Gibbs, B.G.; Jarvis, J.A.; Rossi, G. The Relative Age Effect Reversal among the National Hockey League Elite. PLoS ONE 2017, 12, e0182827. [CrossRef]

13. Ashworth, J.; Heyndels, B. Selection Bias and Peer Effects in Team Sports: The Effect of Age Grouping on Earnings of German Soccer Players. J. Sports Econ. 2007, 8, 355-377. [CrossRef]

14. Treadway, D.C.; Adams, G.; Hanes, T.J.; Perrewé, P.L.; Magnusen, M.J.; Ferris, G.R. The Roles of Recruiter Political Skill and Performance Resource Leveraging in NCAA Football Recruitment Effectiveness. J. Manag. 2014, 40, 1607-1626. [CrossRef]

15. Pawlowski, T.; Breuer, C.; Hovemann, A. Top Clubs' Performance and the Competitive Situation in European Domestic Football Competitions. J. Sports Econ. 2010, 11, 186-202. [CrossRef]

16. Fuchslocher, J.; Romann, M.; Gulbin, J. Strategies to Support Developing Talent. Schweiz. Z. Sportmed. Sporttraumatol. 2013, 61, $10-14$.

17. Herm, S.; Callsen-Bracker, H.-M.; Kreis, H. When the Crowd Evaluates Soccer Players' Market Values: Accuracy and Evaluation Attributes of an Online Community. Sport Manag. Rev. 2014, 17, 484-492. [CrossRef]

18. Gavião, L.O.; Sant'Anna, A.P.; Alves Lima, G.B.; de Almada Garcia, P.A. Evaluation of Soccer Players under the Moneyball Concept. J. Sports Sci. 2020, 38, 1221-1247. [CrossRef]

19. Atanasov, P.; Rescober, P.; Stone, E.; Swift, S.A.; Servan-Schreiber, E.; Tetlock, P.; Ungar, L.; Mellers, B. Distilling the Wisdom of Crowds: Prediction Markets vs. Prediction Polls. Manag. Sci. 2017, 63, 691-706. [CrossRef]

20. Bryson, A.; Gomez, R.; Zhang, T. All-star or benchwarmer? Relative age, cohort size and career success in the NHL. In Breaking the Ice; Springer: Berlin/Heidelberg, Germany, 2017; pp. 57-91.

21. Gyimesi, A.; Kehl, D. Relative Age Effect on the Market Value of Elite European Football Players: A Balanced Sample Approach. Eur. Sport Manag. Q. 2021, 1-17. [CrossRef]

22. Schorer, J.; Deja, J.; Steingröver, C.; Baker, J.; Loffing, F.; Helsen, W.; Wattie, N. The Association of Two Relative Age Effects and Estimated Money Value in Elite Soccer. J. Exerc. Mov. Sport 2017, 49, 128.

23. Herberger, T.A.; Wedlich, F. Does Selection Bias Matter in Football Players' Valuation? A Crowdsourced Valuation Approach on Players' Athletic Characteristics. J. Glob. Sport Manag. 2017, 2, 196-214. [CrossRef]

24. Olivier, J.; Bell, M.L. Effect Sizes for $2 \times 2$ Contingency Tables. PLoS ONE 2013, 8, e58777. [CrossRef] [PubMed]

25. Ramos-Filho, L.; Ferreira, M.P. The Reverse Relative Age Effect in Professional Soccer: An Analysis of the Brazilian National League of 2015. Eur. Sport Manag. Q. 2021, 21, 78-93. [CrossRef]

26. Perez-Gonzalez, B.; Fernandez-Luna, A.; Castillo, D.; Burillo, P. Are European Soccer Players Worth More If They Are Born Early in the Year? Relative Age Effect on Player Market Value. Int. J. Environ. Res. Public Health 2020, 17, 3301. [CrossRef] [PubMed] 